\title{
Epstein-Barr virus co-infection in a patient with dengue fever presenting with post-infectious cerebellitis: a case report
}

\author{
Suneth Karunarathne*, Yapa Udayakumara and Harshini Fernando
}

\begin{abstract}
Introduction: Post-infectious cerebellitis is an acute form of inflammatory encephalitis mainly limited to the cerebellum. It is commonly found in children, especially after viral infections such as Epstein-Barr virus. Postinfectious cerebellitis presents with acute onset dysarthria and ataxia. To the best of our knowledge, this is the first case report of post-infectious cerebellitis in a patient with both dengue and Epstein-Barr viral infection confirmed on serology.

Case presentation: A 43-year-old Sri Lankan Sinhala man presented with an acute febrile illness associated with thrombocytopenia. While being managed as uncomplicated dengue fever, our patient developed dysarthria, ataxia and cerebellar signs. Our patient's infectious disease screen was positive for both dengue and Epstein-Barr specific immunoglobulin M. A cerebrospinal fluid analysis was suggestive of viral meningoencephalitis while cerebrospinal fluid serology was positive for dengue immunoglobulin G. T2-weighted magnetic resonance images were consistent with post-viral cerebellitis. The patient was given full supportive care and he made an uneventful complete recovery.

Conclusion: There have been no previously reported cases of post-infectious cerebellitis associated with both Epstein-Barr and dengue viral infections confirmed by serology. Our patient's clinical features and findings on the imaging studies were consistent with post-viral cerebellitis. This report highlights the need to screen for other possible more common etiologies of a particular presentation before coming to a specific diagnosis based on initial findings. Uncomplicated cases of cerebellitis can be successfully managed with appropriate supportive measures with good prognosis, as in this case.
\end{abstract}

\section{Introduction}

Post-infectious cerebellitis is an inflammatory disorder resulting in acute cerebellar dysfunction. Occurring most commonly in young children, it is an encephalitis largely restricted to the cerebellum [1].

Most of the reported cases of post-infective cerebellitis were due to chickenpox, Coxsackie virus, Epstein-Barr virus (EBV), Mycoplasma pneumonia and human immunodeficiency virus [2]. Despite an extensive literature survey, we could not find any reported cases of cerebellitis following dengue virus infection. There were no previously reported cases of acute post-infective cerebellitis in Sri Lanka due to any etiology.

* Correspondence: suneth871@gmail.com

Ward 49, National Hospital of Sri Lanka, Regent Street, Colombo 08, Sri Lanka

\section{Case presentation}

A 43-year-old previously healthy Sri Lankan Sinhala man was admitted with an acute febrile illness lasting for three days. He had high fever associated with severe myalgia, arthralgia and headache. He also had vomiting associated with a severe loss of appetite for two days. There was no photophobia. He did not complain of cough, chest pain or shortness of breath. There was no dysuria, increased frequency of urination, loin pain, diarrhea or abdominal pain. He did not have any bleeding manifestations. He had no history of skin rash or joint swelling. He had not noticed any significant reduction of urine output and his urine color was normal.

On examination, our patient was febrile and appeared ill. He was not icteric and not pale. There was no cervical lymphadenopathy. There was a mild conjunctival

\section{()


injection but no conjunctival hemorrhages. There were no peripheral stigmata to suggest bacterial endocarditis. Neck stiffness and Kernig's sign were absent. There were no features of joint inflammation but his muscles were mildly tender. No skin rashes or eschars were observed.

A cardiovascular examination found our patient to be tachycardic with a regular pulse rate of 104 beats per minute. His jugular venous pressure was not elevated. His blood pressure was $110 / 68 \mathrm{mmHg}$ with no postural decline. His heart was in dual rhythm and there were no murmurs. His apex beat was not deviated.

He was not dyspnoic and had a respiratory rate of 16 breaths per minute. His breath sounds were symmetrically vesicular and there was no evidence of consolidation. No rhonchi or crepitations were observed.

His abdomen was soft to superficial palpation. There were no abnormal masses on deep palpation and his liver and spleen were not palpable, nor were there any ballotable masses. There was no free fluid.

A nervous system examination revealed an alert and conscious middle-aged man who was mildly distressed due to headache and myalgia. A cranial nerve examination and neurological examination did not reveal any abnormality and he had a normal gait.

Basic laboratory investigations were sent and our patient was initially managed as having an unspecified viral fever pending results of the investigations. A full blood count revealed his hemoglobin level to be $13.4 \mathrm{~g} /$ $\mathrm{dL}$, his white blood cell count (WBC) 4400/ $\mu \mathrm{L}$ (neutrophils, 76\%; lymphocytes, 24\%) and a platelet count of $48,000 / \mu \mathrm{L}$. His serum creatinine was $83 \mu \mathrm{mol} / \mathrm{L}$, serum sodium was $141 \mathrm{mmol} / \mathrm{L}$ and potassium was $3.7 \mathrm{mmol} /$ L. His liver enzyme results were as follows: aspartate transaminase, $153 \mathrm{U} / \mathrm{L}$, alanine transaminase, $207 \mathrm{U} / \mathrm{L}$; and alkaline phosphatase, $387 \mathrm{U} / \mathrm{L}$. His total protein level was $70 \mathrm{~g} / \mathrm{dL}$ with albumin of $43 \mathrm{~g} / \mathrm{dL}$. His international normalized ratio was 0.97 and activated partial thromboplastin time 32 seconds.

The initial investigations were compatible with dengue fever. Blood was taken to screen for the dengue antibody and blood cultures were sent. His fluid intake was maintained according to the national guidelines on dengue fever, as there was a widespread dengue epidemic with hundreds of patients getting admitted daily. His fever was treated symptomatically with paracetamol.

His fever settled on the fourth day of fever and our patient was symptomatically better. However, he developed mild slurring of speech six days after the onset of fever. On the seventh day, he had marked slurring of speech and he found it difficult to walk due to severe unsteadiness. An examination revealed a bilaterally impaired finger-to-nose test and heel-to-shin test. He had dysdiadochokinesia and an ataxic gait. There was no nystagmus. An examination of the fundus of his eye did not reveal any abnormality. An examination of his cranial nerves continued to be normal. There were no peripheral sensory or motor deficits. His deep tendon reflexes and plantar reflexes remained normal.

Due to the sudden onset of bilateral cerebellar signs, an urgent non contrast computed tomography scan was performed. There were bilateral hypodense areas in his cerebellum but his ventricles and cerebral hemispheres appeared normal. A magnetic resonance imaging (MRI) scan of his head was performed, which revealed bilateral diffuse hyperintense areas in his cerebellar hemispheres spreading across the vermis (Figures 1 and 2). The appearance in the MRI scan was compatible with acute postinfective cerebellitis. Serological studies were performed for the possible viral etiologies that can cause cerebellitis. Hepatitis B and C serology, herpes simplex virus serology and Japanese encephalitis immunoglobulin $\mathrm{M}$ were negative. An enzyme linked immunosorbent assay (ELISA) for human immunodeficiency virus was negative. Dengue virus immunoglobulin M (IgM) and immunoglobulin G (IgG) were both detected in our patient's serum on day six after the onset of the symptoms. EBV IgM antibody was detected in his blood by ELISA on the eighth day of illness. Serological studies for Salmonella typhi and paratyphi were negative. A cerebrospinal fluid (CSF) analysis showed a WBC of 10 cells/ $\mu \mathrm{L}$ (lymphocytes, nine cells and neutrophils, one cell), red blood cells 1 cell $/ \mu \mathrm{L}$, proteins $0.88 \mathrm{~g} / \mathrm{dL}$ and sugar $3.1 \mathrm{mmol} / \mathrm{L}$ with a random blood sugar of 5.4 $\mathrm{mol} / \mathrm{L}$, all of which were compatible with viral central

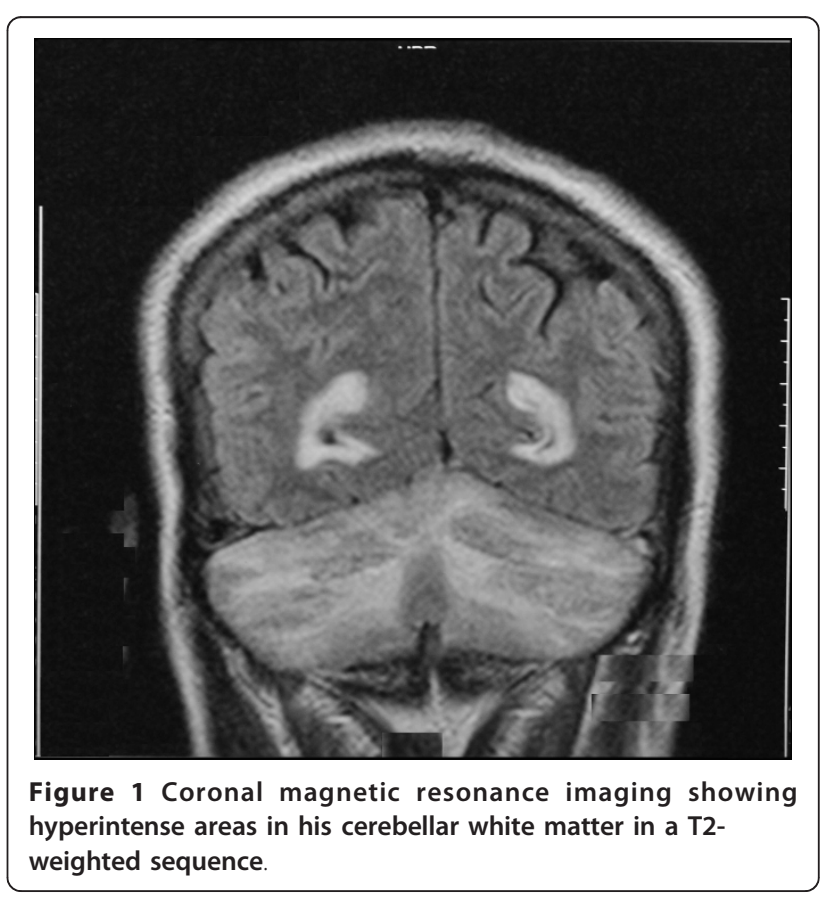




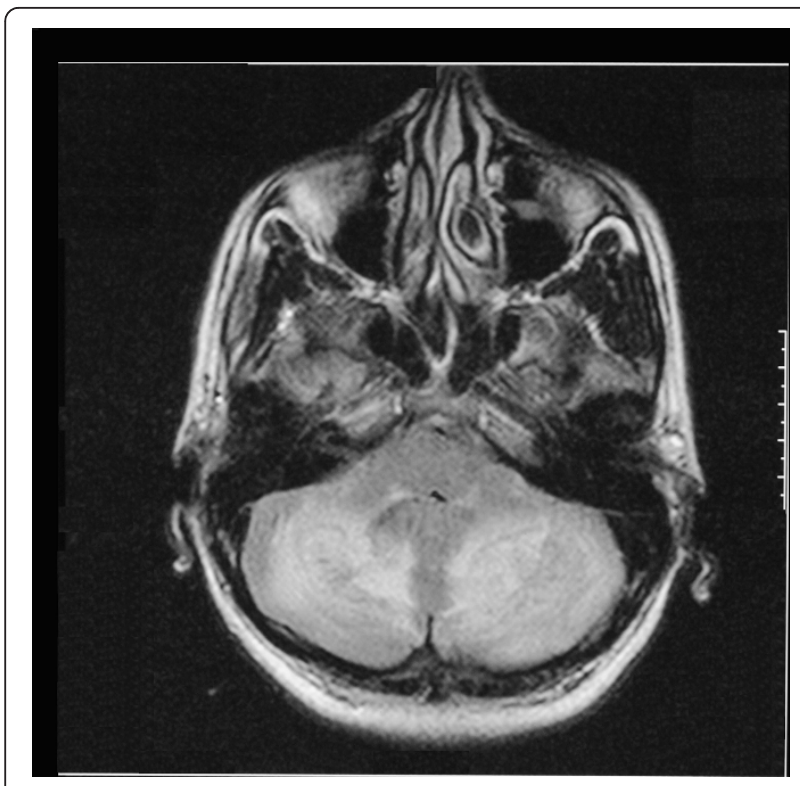

Figure 2 Axial magnetic resonance imaging showing hyperintense areas in his cerebellar white matter and ventricular enhancement in a T2-weighted sequence.

nervous system infection. Cerebrospinal fluid cultures were negative and viral studies were negative for Herpes simplex virus, EBV antibody and Japanese encephalitis virus. Dengue IgG was detected in his CSF while IgM was negative. Dengue virus non-structural protein 1 antigen was not detected in his CSF.

Dependent on the clinical findings and serology, a diagnosis of post-infectious cerebellitis was made. Our patient was managed with maximum supportive care and physiotherapy combined with gait training. Speech therapy was also commenced. At discharge two weeks after the onset of symptoms, our patient was able to walk without support and his speech was markedly improved. His platelet count, WBC and differential counts were within normal limits at the time of discharge.

\section{Discussion}

Since our patient had serological evidence of both recent dengue and EBV infections we could not attribute his clinical picture to a single viral agent. However, the clinical picture was more in favour of dengue fever rather than that of infectious mononucleosis. Usually, post-viral cerebellitis follows a benign course without life-threatening complications [3]. Acute hydrocephalus is one of the more serious among reported complications [4].

Acute cerebellitis when associated with cerebellar swelling, hydrocephalus and brainstem compression can be life-threatening, although these complications are rarely observed [5]. MRI shows hyperintense signals of cerebellar white matter in T2-weighted sequences, which is a strong indication of a diagnosis of acute cerebellitis (Figures 1 and 2). C-shaped cerebellar white matter T2 hyperintensity demonstrated in post-infectious cerebellitis is caused by cerebellar white matter vasogenic edema [6]. Resolution of the hyperintense areas in the cerebellar cortex can be associated with recovery from the clinical manifestations, although mild cerebellar atrophy may be seen in follow up MRI scans [7].

Although commonly due to viruses, bacterial infections have also been associated with cerebellitis, including Borrelia burgdorferi (Lyme disease), Mycoplasma pneumoniae, Legionella and Coxiella burnettii (Q fever). In addition, cerebellitis may follow immunizations, such as hepatitis, smallpox and measles vaccination. In many cases, however, the precise causative agent is not isolated [1]. In uncomplicated cases of cerebellitis treatment is usually supportive, as was the case in our patient.

\section{Conclusion}

To the best of our knowledge, there have been no previously reported cases of cerebellitis associated with dengue viral infection. Despite having clinical and laboratory evidence suggestive of dengue, other possible etiological agents for post-infectious cerebellitis were sought as this was an unusual presentation of dengue. Besides describing interesting MRI features of postinfectious cerebellitis, this case illustrates the importance of having an open mind when an unusual presentation of a known disease is investigated. It therefore improves our understanding of clinical and laboratory features of post-infectious cerebellitis and also provides insight into unusual clinical presentations in general.

\section{Consent}

Written informed consent was obtained from the patient for publication of this case report and any accompanying images. A copy of the written consent is available for review by the Editor-in-Chief of this journal

\section{Authors' contributions}

SK, YU and HF were involved in the management of the patient. SK prepared the manuscript. YU and HF provided valuable input during the preparation of the manuscript. All authors read and approved the final manuscript.

\section{Competing interests}

The authors declare that they have no competing interests.

Received: 11 September 2011 Accepted: 30 January 2012 Published: 30 January 2012

\section{References}

1. No authors listed: Case records of the Massachusetts General Hospital. Weekly clinicopathological exercises. Case 38-1996. An 18-year-old man with severe headache, pleocytosis, and ataxia. N Engl J Med 1996, 335(24):1829-1834 
2. Teive HA, Zavala JA, Iwamoto FM, Bertucci-Filho D, Werneck LC: Acute cerebellitis caused by Epstein-Barr virus: case report. Arq Neuropsiquiatr 2001, 59(3A):616-618.

3. Connolly AM, Dodson WE, Prensky AL, Rust RS: Course and outcome of acute cerebellar ataxia. Ann Neurol 1994, 35:673-679.

4. Melaiki TB, Thabet F, Anjum SB, Amin A: Acute cerebellitis with hydrocephalus and brainstem compression. Arch Dis Child 2007, 92:38.

5. Levy El, Harris AE, Omalu RL, Hamilton RL, Branstetter BF, Pollack IF: Sudden death from fulminant cerebellitis. Pediatr Neurosurg 2001, 35:24-28.

6. Montenegro MA, Santos SL, Li LM, Cendes F: Neuroimaging of acute cerebellitis. J Neuroimag 2002, 12:72-74.

7. Dogulu F, Onk A, Kaymaz M, Kardes O, Baykaner MK: Acute cerebellitis with hydrocephalus. Neurology 2003, 60:1717.

doi:10.1186/1752-1947-6-43

Cite this article as: Karunarathne et al:: Epstein-Barr virus co-infection in a patient with dengue fever presenting with post-infectious cerebellitis: a case report. Journal of Medical Case Reports 2012 6:43.

\section{Submit your next manuscript to BioMed Central} and take full advantage of:

- Convenient online submission

- Thorough peer review

- No space constraints or color figure charges

- Immediate publication on acceptance

- Inclusion in PubMed, CAS, Scopus and Google Scholar

- Research which is freely available for redistribution

Submit your manuscript at www.biomedcentral.com/submit 